\title{
Esophageal squamous cell cancer susceptibility: Environmental and nutritional associations reveal a universally applicable pathogenesis scenario (Review)
}

\author{
SCHALK JANSE VAN RENSBURG $^{1}$ and SUSAN JANSE VAN RENSBURG ${ }^{2}$ \\ ${ }^{1}$ Private Bag X11, Amber Lee, Unit 27, Howick 3290; ${ }^{2}$ South African Environmental Observation Network (SAEON), \\ Grasslands Node, Pietermaritzburg 3202, South Africa
}

Received June 16, 2019; Accepted September 25, 2019

DOI: $10.3892 /$ wasj.2019.24

\begin{abstract}
Some epidemiological features, such as marked variations of incidence between geographical regions, are unique to esophageal squamous cell carcinoma (ESCC). The objective of this evaluation of only ESCC was to collate those factors that have quantitative and biological credibility, enabling the deduction of an etiological hypothesis to explain this, based on facts. Worldwide, $80 \%$ of new cases arise in less developed regions and are generally not associated with alcohol or tobacco use. Abstinence was also usual in some European localities where a high incidence occurred in certain remote regions, as well as in patients with malabsorption syndromes. All had multiple micronutrient deficiencies, resulting in atrophy and chronic esophagitis that preceded clinical carcinomas. The esophagus has an extraordinarily high cell replication rate requiring higher micronutrient nutrition than other epithelia. Stable communities worldwide, whose staple diet was maize (corn) or wheat were invariably at high risk, whereas the use of nutritious food sources resulted in an unusually low risk. The susceptibility of animals fed such diets mirrored the human situation exactly. Pertinent deficiencies identified thus far are riboflavin, nicotinamide, molybdenum (Mo), magnesium (Mg), manganese (Mn), selenium (Se) and zinc ( $\mathrm{Zn}$ ). Subclinical deficiencies of these have been shown to enhance the susceptibility of rats to ESCC.
\end{abstract}

Correspondence to: Dr Schalk Janse Van Rensburg, Private Bag X11, Amber Lee, Unit 27, 8 Nyala Lane, Howick 3290, South Africa E-mail: tpmjvr@gmail.com

Ms. Susan Janse van Rensburg, South African Environmental Observation Network (SAEON), Grasslands Node, 1 Peter Brown Drive, Pietermaritzburg 3202, South Africa

E-mail: sue@saeon.ac.za

Abbreviations: ESCC, esophageal squamous cell carcinoma; IARC, International Agency for Research on Cancer; PAHs, polycyclic aromatic hydrocarbons; B2, riboflavin; B3, nicotinamide, niacin, nicotine acid

Key words: esophageal squamous cell carcinoma, pathogenesis, etiology, micronutrients, environment, carcinogens, mycotoxins
Extraordinary carcinogen exposure has only been shown in rural epidemic regions. Geologically determined poor soils yield plants vulnerable to fungal pathogens, some of which are carcinogenic to the rat esophagus. Tobacco exerts its synergistic effects on the nutritionally impaired esophagus. Nitrosamine exposure is not unusual; however, regenerative stress such as that caused by constrictions and hot drinks increase the risk. The common underlying determinant of susceptibility worldwide is chronic deficiencies of multiple micronutrients that normally maintain the integrity of the esophagus and are necessary for a number of anti-carcinogenic mechanisms. Micronutrient fortification of staple foods appears to markedly reduce the risk.

\section{Contents}

1. Introduction

2. Populations studied

3. Environmental similarities in ESCC epidemic regions

4. Nutrition studies

5. Esophageal epithelial pathology possibly related to nutrition

6. Mycotoxin contamination of food

7. Other potentially harmful factors

8. Discussion and conclusions

\section{Introduction}

Of all esophageal cancer cases diagnosed globally, $88 \%$ are squamous cell carcinomas (ESCC) and of these, approximately $80 \%$ occur in low-income regions of Asia and Africa $(1,2)$. There are a number of unique epidemiological features of ESCC. These include: Geographically determined risk; sex ratios that approach or equal parity in high epidemic regions; increases of occurrence from virtually unknown in Africa to high-risk within two or three decades; gastric atrophy prevalent in some ESCC high risk populations (3); and alcohol consumption and smoking, that have highly variable impacts on different populations. These impacts have also changed with time. For example, widespread indulgences in Africa for at least 300 years were 
without recorded cases in ESCC, until around the 1940s when there was a marked increase in incidence, stabilizing in the 1960s. Intriguing is the frequency of ESCC in isolated groups in Europe, where no unusual source of carcinogens can be identified. Curiously, it has also been found that chickens belonging to Chinese patients with ESCC are also at high risk (4).

Current perceptions of nutritional aspects participating in etiology have been evaluated in detail by the Continuous Update Project, 2018 (1). They concluded that the only strong aggravating factors are alcohol intake and the drinking of 'Mate', a South American herbal tea, which is consumed at a very hot temperature. Etiological studies still cannot verify which factors play a dominant role in the pathogenesis of ESCC (2). Inconclusive results of supplementation trials have discouraged scientists from pursuing the micronutrient hypothesis further (5). A recent review (3) did not list nutrition as a risk factor.

We consider that it is important to distinguish between risk factors that predispose the esophageal epithelium to neoplastic transformation, rather than merely studying the effects on cells that have commenced malignant transformation. Thus, exposures identified over the first few decades of life could be revealing.

The objective of this brief review was to assess all associations possibly having relevance to susceptibility that have been made worldwide. Interpretations were limited to those factors having quantitative associations and biological credibility with only ESCC etiology. An etiological hypothesis could thus be deduced using credible factual information.

\section{Populations studied}

A number of stable communities whose survival depended on a subsistence economy existed worldwide up to about the middle of the 20th century. Epidemiologists recorded vast variations in their susceptibility to ESCC. These varied from virtually unknown to be the major cause of adult deaths (6). Such disparities of incidence constituted unique study models that could yield vital clues regarding etiology.

European groups living a largely subsistence lifestyle in remote regions still existed up to a few decades ago. A high incidence of ESCC in women living in such circumstances was recorded in Scotland, coastal regions of Wales and in Ireland (7). The disease was also prevalent in Scandinavian countries, often associated with the Plummer-Vinson (Patterson-Kelly) syndrome (8). Sporadic cases have been strongly associated with malabsorption syndromes due to various causes, such as achalasia, coeliac disease, Crohn's disease and dyspepsia (9). Esophageal strictures that resulted from a variety of causes were often the site of carcinomas (10). Several case-control studies on patients in the USA and Europe have been informative (11-15).

Epidemiological studies have been reviewed for China (2,16-18), Iran (19-21), Africa (6,10,22-24), USA and globally (25). Exceedingly high incidence rates have been recorded in the 'Asian esophageal cancer belt' encompassing Eastern Turkey, Iran, Kazakhstan, Turkmenistan, Mongolia and Northern China. Loci in the Eastern Cape in South Africa also had similar rates. High incidence rates have also be reported in East Africa (including Tanzania, Kenya and Uganda up to Sudan), as illustrated by Odera et al (26). Reports from South America seem to mirror the East and Southern African situation. The three most well-studied 'epidemic' loci, where incidence rates may exceed 100 cases per a 100,000 population, are the Eastern Cape (former Transkei region) in South Africa, provinces such as Linxian in China, and the Caspian littoral of Iran. Large rural and peri-urban indigent populations may have 'endemic' rates of up to 20 per 100,000 individuals, while 'westernized' populations are considered as relatively low-risk; nevertheless, cancer registers exhibit much variation. Traditional African communities in West Africa adhering to ancient lifestyle habits and having the lowest socio-economic status are known to have virtually no risk (24).

\section{Environmental similarities in ESCC epidemic regions}

Several millions of years ago in the Eastern Cape region (former Transkei) in South Africa, lava seeped up through cracks and solidified on reaching the cooler surface. Thus, mineral-rich dolerite dykes were formed that typically give rise to red soils, interspersed with ancient sedimentary soils, usually grey in color and considerably leached out of soluble minerals. The end result is a patchy landscape with variable availability of minerals, depending on location and geological parent material, available for soil formation.

Early investigations in the Eastern Cape in South Africa on the location of homes of cancer patients were reported by Burrell in 1962 (27). The author noted that while some settlements harbored numerous patients, adjacent valleys had few or none. The difference was ascribed to the observed fertility of the soil. A geological survey of cluster and free areas was reported the same year (28). An abnormally high incidence of ESCC cases was found in areas with eroded sedimentary soils termed 'Beaufort soils'. Unaffected communities lived largely on fertile soils derived from mineral-rich dolerite. Limited analyses revealed that Beaufort sediments had much lower concentrations of manganese $(\mathrm{Mn})$, iron $(\mathrm{Fe})$, magnesium $(\mathrm{Mg})$ and sodium $(\mathrm{Na})$. The authors concluded that 'trace element imbalance was most likely the root of the problem' (28)

Later, clustering of cases on infertile soils was statistically confirmed and the list of low levels of minerals extended to boron (B), molybdenum (Mo), zinc $(\mathrm{Zn})$ and copper $(\mathrm{Cu})$, while the levels of heavy metals, such as lead $(\mathrm{Pb})$ tended to be excessive (29). Meanwhile, a cancer registration program along the Southern shores of the Caspian Sea in Iran commenced in 1968 , followed by an extensive soil survey. The association of a high risk of developing ESCC with saline and alkaline soils was found to be 'striking' (20). It was concluded that the availability to plants of $\mathrm{Fe}, \mathrm{Mn}, \mathrm{B}, \mathrm{Cu}$ and $\mathrm{Zn}$ would be severely inhibited in such soils. The climate was also drier and the major crop was cotton with wheat being subdominant. World soil maps indicate that similar conditions are likely to prevail in the highest risk regions of China, where cotton is also largely produced. Chinese investigators analyzed a large number of food and water samples from high-, medium- and low-risk counties in Henan Province. The data revealed an inverse correlation between ESCC mortality and the contents of Mo, Mn, $\mathrm{Zn}, \mathrm{Mg}$, nickel (Ni), Fe, iodine (I), chlorine ( $\mathrm{Cl}$ ), potassium (K), Na and $\mathrm{P}(17)$. In China, vast differences in risk, up to 100 -fold, were also recorded in adjacent regions $(4,30)$. 
Comparative studies of Iranian soils with those found in Africa revealed marked similarities. The results confirmed the association of a low risk of developing ESCC with high potential soils, high organic matter contents and low subsoil $\mathrm{pH}$ values. In addition, both high ESCC regions had low Mn levels that adversely affected crop production (31).

Plants growing in low-fertility soils characteristic of patients' gardens in Africa were generally stunted and exhibited several symptoms typically observed with various mineral deficiencies. Aided by 'diagnostic' mineral leaf injections, solid evidence was obtained that maize, bean and pumpkin plants were deficient in $\mathrm{Mo}, \mathrm{Fe}, \mathrm{Cu}, \mathrm{Zn}, \mathrm{B}$ and $\mathrm{Mn}$ (22). Chemical analyses of maize leaves taken from high- and low-risk regions confirmed common deficiencies in nitrogen $(\mathrm{N}), \mathrm{P}, \mathrm{Zn}$, $\mathrm{Mn}$ and low $\mathrm{K} / \mathrm{Mg}$ ratios in high-risk regions (31). Low crop productivity was not due solely to Mo deficiencies, but was also ascribed to N, K and most strikingly, to Mn deficiencies.

Water analyses in African high-risk ESCC regions revealed lower concentrations of $\mathrm{Mn}, \mathrm{B}$, fluorine (F), cobalt (Co), Se, chromium $(\mathrm{Cr})$ and low $\mathrm{pH}$ values. However, the levels of $\mathrm{Na}$, $\mathrm{Cu}, \mathrm{Cl}, \mathrm{Pb}$ and nitrate $\left(\mathrm{NO}_{3}\right)$ were increased. Mo was generally deficient $(29,31)$. Water sources in all three epidemic regions predominantly yield soft waters that are deficient in $\mathrm{Ca}, \mathrm{Mg}$ and several beneficial trace elements. They are termed 'aggressive' and tend to accumulate heavy elements, such as $\mathrm{Pb}$ and mercury $(\mathrm{Hg})$, as well as excessive F levels. The World Health Organization has identified well-known belts having a high F hazard, the largest coincides almost exactly with the 'Asian esophagus cancer belt', while the second is in Africa, extending from Eretria along the East African Rift to Malawi, also a high-risk region (32). A $42 \%$ excess risk of mortality from ESCC in relation to the use of soft water in Taiwan has been recorded (33). A significant trend to a decreased risk with increasing $\mathrm{Mg}$, but not Ca levels was also recorded (30). Hard water has many positive health aspects and, for instance, supplies sufficient Mg to rectify marginal deficiencies (34).

\section{Nutrition studies}

Worldwide studies on basic dietary staples have revealed a marked association with ESCC. The fortuitous choice of the type of cereal that constitutes the bulk of the diet in those adhering to a simple lifestyle is the main determinant of risk (35). Without exception, all communities subsisting primarily on maize (corn) or wheat have a high risk of ESCC. When rice is the staple, the risk is usually intermediate. Exceedingly low risks are invariable when the dietary staple consists of sorghum, millet, cassava, yams or peanuts, or a combination of these. The human risk associated with these staples has been shown to coincide exactly with that of rats fed the same staples (36).

There is a large difference in the concentration of certain micronutrients in high- and low-risk dietary staples. If food energy is exclusively obtained from dietary staples, incidental intakes of, in particular, $\mathrm{Zn}, \mathrm{Mg}$, riboflavin and nicotinamide will be deficient for the high-risk staple grains, but adequate for foods associated with low risk (36). Subclinical deficiencies in all these micronutrients individually have been found to markedly enhance carcinogenesis in rats (37). It is now known that Mo and Se concentrations are also much higher in low-risk staples.
Modern plant breeding techniques designed to produce cultivars that increase yield, invariably enhance the starch component of the kernel. The majority of micronutrients are concentrated in the husk and germ components. Milling and extraction processes designed to produce flour from which a 'soft mouth feel' product may be made, vastly reduce the amounts of micronutrients. Similarly, brown rice is nutrient-rich, but when 'highly polished' would be so depleted as to fall into the category of high-risk staples. The lifestyle of semi-urbanized Africans having a moderately high risk of developing ESCC was investigated in detail (38). Of numerous parameters measured, the daily consumption of unfortified commercial maize meal had the highest relative risk of 5.7 (38).

The notorious dietary inadequacy of indigent alcoholics, who often obtain half their energy requirements from alcohol, is well known. Historical reports on some westernized populations having a high risk have excluded any role of alcohol or tobacco. These include individuals residing in remote parts of Wales, Northwest Scotland, Swedish women, Plummer-Vinson patients and even nuns in England that had an exceptionally frugal lifestyle. Without exception, all subsisted primarily on a mono-cereal diet. Urbanized Americans at a high risk of ESCC are usually associated with a lower socio-economic status, smoking and alcoholism. However, a study that corrected for the above-mentioned risks found an independent effect of a lower consumption of meat, fish, fruit, vegetables, dairy products and eggs. The relative risk between extremes was 14 (15).

Early attempts at measured dietary intake studies were performed in Northern Iran $(14,19,21)$. The findings indicated widespread riboflavin deficiencies that were verified by clinical studies and later, biochemically. Subsequently, the concentration of $\mathrm{Zn}$ in hair in high-risk healthy individuals was shown to be low (39). A case-control nutrient intake study implicated generally low nutrient intakes, but most significantly, low niacin intakes (40).

Initial Chinese studies reported that the Mo contents in serum, hair and urine samples were significantly lower in high-risk regions (Linxian) than those from low-risk localities (17). Trace elements in 871 hair samples from five regions were then analyzed. An inverse correlation was found between the risk of ESCC and the contents of $\mathrm{Mg}$, Mo and $\mathrm{Zn}$ in hair samples. A dietary intake study coupled with blood sampling was reported by Yang et al (41); it encompassed high- and moderate-risk localities. Whereas riboflavin deficiency was widespread and vitamin $\mathrm{A}$ and ascorbate values were rather low, there were no significant differences in the status of these vitamins. Carotene levels, however, were twice as high in the higher risk regions. Fruit consumption in the low-risk area tended to be double that of the high-risk regions. A later study on the same high-risk populations in China revealed that the Se levels were abnormally low (42). A prospective study of the Chinese population conducted over a period of 5.5 years revealed a significant inverse association with the risk of developing ESCC and initial Se levels (43). Dietary intake studies confirmed a strong inverse dose-response trend of $\mathrm{Zn}$ and $\mathrm{Se}$ to the risk of ESCC (44), as was also the case in the Rift Valley region of East Africa (24).

In Africa, dietary and biochemical nutritional status studies were conducted in Southern Africa, within the Eastern Cape (formally known as Transkei) in South Africa $(45,46)$. 
Biochemical analyses confirmed that the mean values of protein, albumin, vitamin $\mathrm{A}$ and $\mathrm{P}$ were generally acceptable. Inadequate values were recorded for nicotinic acid (74\%), $\mathrm{Mg}$ $(60 \%)$, vitamin C $(55 \%)$ carotene $(53 \%)$, riboflavin $(41 \%), \mathrm{Ca}$ $(35 \%)$ and $\mathrm{Zn}(27 \%)$. Low $\mathrm{Mg}$ values were particularly marked in children aged 2 to 9 years. A third of all young girls had Zn values that were unacceptably low.

Within the same region, hair samples were obtained from 42 healthy males and 9 ESCC cancer cases (47). They were analyzed by neutron activation analysis for the content of 17 minerals, excluding $\mathrm{Se}, \mathrm{Mo}, \mathrm{Mg}$ and $\mathrm{Pb}$. A comparison between healthy males and cancer cases revealed highly significantly suppressed levels of $\mathrm{Cr}$ and high concentrations of $\mathrm{Hg}$ in the cancer cases. Aluminium (Al) and $\mathrm{Zn}$ levels also tended to be low in the cancer patients. Correlations between the values of healthy males only, and the cancer rate of their district of origin were found for $\mathrm{Hg}$ and $\mathrm{Al}$. $\mathrm{Hg}$ levels increased significantly with the increased cancer rate. Al levels however, decreased markedly with increased cancer rates, to an extent that it was a good indicator of cancer risk. These findings correlate well with the identified geochemical environmental risks; for instance, $\mathrm{Al}$ is believed to be important in retaining nutrient elements in the soil (48). The mean hair $\mathrm{Zn}$ levels were similar to the trends of those reported in China, but were not uniquely low.

A meticulous study design was utilized to assess the nutritional status of Se in the Eastern Cape (former Transkei) in South Africa (49). Within a high-risk ESCC area, occupants of households with previously recorded ESCC cases had significantly lower levels of Se than subjects from households without known cases. Ostensibly 'normal' subjects found to have pre-malignant or malignant esophageal cytological changes were even lower $(54 \mathrm{ng} / \mathrm{ml})$, significantly so compared to subjects without such lesions $(68 \mathrm{ng} / \mathrm{ml})$. An inverse association was found between the Se status and the degree of cytological abnormalities. Within Europe, Se levels may also be suboptimal. A prospective study conducted in The Netherlands on the Se content of toenail clippings revealed an inverse association with ESCC over the next 16 years (12).

Historical studies invariably reported a protective effect of vegetable and fruit consumption against ESCC, and it still applies to populations worldwide. In Holland, for example, inverse relationships, particularly with current smokers have been reported (13). A prospective European study found significant inverse associations with ESCC and fruit alone, as well as with vegetables when combined with fruit (11). A meta-analysis on the consumption of only citrus fruit reported a $>30 \%$ protection against the risk of ESCC (50). Further meta-analysis on citrus intake determined a relative risk of 0.59 (51).

Beneficial effects of fruit and vegetables are, in addition to their nutrient content, often ascribed to their phytochemical contents, many of which are antioxidants. Oranges, for example contain some 170 different phytochemicals in addition to $>60$ flavonoids. A review conducted in 2013 concluded that bioactive compounds in orange juice could medicate inflammatory responses, as judged by a reduction in inflammatory markers in plasma (52). Indeed, a single blind crossover trial in humans confirmed that orange juice does reduce markers, such as c-reactive proteins, in the circulation (53).
No single plant compound that can match the effects of orange juice has been identified to date. Nutrients taken with $248 \mathrm{ml}$ of juice daily can make an appreciable contribution to daily requirements. According to the USDA database (https://fdc.nal.usda.gov/fdc-app. html\#/food-details/169097/nutrients), the percentage of some micronutrients thought to be important to maintain integrity of the esophagus would be: Vitamins $\mathrm{B}_{2}(6 \%), \mathrm{B}_{3}(7 \%)$, the elements $\mathrm{Mg}(8 \%)$ and $\mathrm{Mn}(3 \%)$.

\section{Esophageal epithelial pathology possibly related to nutrition}

The highest mitotic index of any epithelium in laboratory animals is observed in the esophagus. Maintaining this regenerative tempo would likely require a high level of metabolic efficiency, largely dependent on good nutrition. For example, if some micronutrients essential for a healthy skin, such as riboflavin, are marginally deficient, pathological changes would first be observed in the esophagus. Pathological changes, now considered to be precancerous, that develop following micronutrient deficiencies in humans and animals, have long been documented (10).

Previously, the effects of consuming a deficient human diet, such as that consumed by households having a history of ESCC cases, on the rat esophagus were studied (54). Within one year on the diet, the epithelia of the majority of animals became exceedingly thin and were sparsely populated with basal epithelial cells. A year later, the epithelia of the majority of animals were irregularly thickened; some exhibited parakeratosis, hyperkeratosis, basal cell hyperplasia, foci of anaplastic cells and dysplasia. Subepithelial accumulations of inflammatory cells and edema were sporadic, as was fibrosis in these older animals. Two of seven three-year old rats died of cancerous growths obstructing the lower third of the esophagus.

Structurally, the human esophagus of course markedly differs from that of rats. In spite of this, a number of studies on changes thought to be precursor lesions have shown some similarities to the scenario observed in rats. Historical reports on Plummer-Vinson syndrome stated that atrophy of the esophageal epithelium was 'well known', as was the case with other malabsorption syndromes known to increase the risk of ESCC in European patients (8,55-60). In a high-risk region of Africa, the esophagi of individuals aged 20-70 years who had died from trauma were examined during the course of forensic autopsies (61). Not one of a series of 85 consecutive examinations was found to be normal. Atrophy of the epithelium was most common, followed by esophagitis and irregular thickenings, up to carcinoma in situ. By contrast, the epithelium of comparatively affluent individuals from a nearby city was invariably smooth with an opaque creamy appearance.

Maximal risk for ESCC is not usually reported before the 5 th or 6th decade of life; however, sporadic cases in teenagers have been reported in high-risk regions $(62,63)$ Changes in the esophagus suggestive of risk have now been reported to be common in children. Chronic esophagitis and basal cell hyperplasia, often forming atypical nodules, were observed in approximately half of those aged from 2-18 years (63). In another study, the majority of Chinese boys at risk that were 
aged 15-20 years had esophagitis that was confirmed histologically. Acanthosis was common and in approximately $10 \%$ of subjects the epithelium was atrophic (64). Exfoliative cytology using brush capsules revealed that in South Africa, individuals aged 15-30 years commonly had esophagitis and to a lesser extent, cellular atypia and dysplasia (65).

Despite evidence of a generalized esophageal disease, clinical carcinomas tend to arise in the mid and lower thirds of the organ. These are normal constriction sites due to pressure from the heart-aortic arch and thicker musculature lower down. The proximal third seems vulnerable in anemic patients who develop post-cricoid webs and dysphagia. This condition was common in cases of Plummer-Vinson syndrome and was also reported in patients suffering from anemia in Southern Iran (66). Strictures resulting from chemical or traumatic damage are also well known to be the site of the primary tumor. Constrictions would impose greater pressure on the regenerative capacity of an impaired epithelium, as well as aggravating exposure of premitotic progenitor cells.

\section{Mycotoxin contamination of food}

Original observations by Burrell et al $(22,27)$ revealed that grains produced in soil having multiple deficiencies were 'heavily mildewed'. They verified this observation by demonstrating that fungal invasion could be obviated by appropriate fertilization of the soil. The fungi in question are plant pathogens that invade the living maturing plant via soil, infected seeds, or airborne infection. Their presence can be insidious and not always obvious, such as that observed with 'storage' fungi, such as Aspergillus. The main plant pathogens were identified as several species of Fusarium of which $F$. moniliforme $(=F$. verticillioides) exhibited a striking positive association with the risk of ESCC over several districts (67). The association was evident even on a micro-scale when high- and low-risk villages were separated by a few kilometers. The levels of $F$. moniliforme toxins, Fumonisin B1 and B2, were found to be 20-fold higher in the high-risk regions when compared with levels in the low-risk regions (68), although it is uncertain whether the Fumonisins are implicated in the disease etiology.

The same team of mycologists (from Africa) visited the homes of cancer patients in the Gonbad region in Iran, where the local wheat had been reported to be infested with various Fusaria (21). They observed that the fungal contamination of local wheat was 'often severe'. Alternaria alternata was dominant in their samples and the majority of strains isolated were toxic to ducklings. When as little as $0.25 \%$ meal molded with Iranian Alternaria or with African F. moniliforme was fed to nitrosamine-treated rats, a highly significant enhancement of carcinogenesis was recorded (69). Moreover, Chinese investigators working independently produced ample evidence that F. moniliforme was very likely to be implicated in the pathogenesis of ESCC. Overtly moldy corn bread produced tumors in rats and they explored the possibility of molds facilitating the production of nitrosamines (17). Attention was also drawn to the high incidence of fungal infection of the esophageal epithelium in cases of dysplasia and cancer.

Long-term feeding studies, utilizing $F$. moniliforme moldy meal incorporated into a semi-synthetic purified rat diet at a rate of as little as $0.5 \%$, confirmed beyond doubt, that $F$. moniliforme produced compounds that were carcinogenic $(70,71)$. Low levels of $0.5 \%$ in the diet produced neoplasms in the forestomach of the majority of rats, but only occasional papillomas in the esophagus. Slightly higher doses produced a number of pathologies in the liver, with several rats developing cirrhosis and hepatocellular carcinomas. The pathological changes were markedly similar to those found when human-prepared food from high-risk households was fed long-term to rats (72). The food contained meal made from hand-sorted maize kernels considered clean by housewives; however, it was found to be heavily contaminated with F. moniliforme (67).

Known quantitative exposures to aflatoxin do not suggest any role of this mycotoxin in ESCC etiology (73). Similarly, high exposure to Fusaria toxins is not associated with an increased risk of developing hepatocellular carcinoma, despite their ability to induce this type of cancer in rats. Compared to primates, the rat liver is known to be more susceptible to hepatocarcinogens.

\section{Other potentially harmful factors}

Nitrosamine intake studied by means of quantitative food surveys were conducted in the Eastern Cape in South Africa and in Iran. The methods used were precise and utilized confirmation by mass spectroscopy and gas chromatography-thermal energy analysis (GLC-TEA), the latter performed at the International Agency for Research on Cancer (IARC) $(21,31)$. All food samples revealed only traces of nitrosamines, very rarely $>1 \mu \mathrm{g} / \mathrm{kg}$. Epidemiological studies exploring possible associations between nitrosamine exposure and ESCC were reviewed in 2006 (74), with inconclusive results. Trace amounts of nitrosamines are now known to be ubiquitous (75).

Since the detailed review on the use of tobacco in all its forms in numerous countries by Warwick and Harrington (10), a number of studies have confirmed the overall deductions (38,76-79). Some enhancement of the risk of ESCC by smoking can be demonstrated in all general populations. However, any effect on well-nourished individuals is difficult to demonstrate.

Undoubtedly tobacco use has a marked effect on those suffering from subclinical multiple micronutrient deficiencies (38). Such a situation would also apply to the usual 'western' chronic alcoholics. Their deficiencies are precipitated by reduced intake, increased metabolic requirements and the promotion of the excretion of several nutrients by alcohol. Alcoholism tends to lead to intestinal alterations similar to the malabsorption syndrome known as coeliac disease (8). There are also several compelling, but theoretical, mechanisms through which alcohol and acetaldehyde may directly promote carcinogenesis (8).

Smoking and alcohol consumption have not been identified as significant factors in any of the major epidemic ESCC rural populations of the world. Both habits are known to have been widely practiced in Africa for at least 300 years. Common was the daily use of pipes, home-grown tobacco and marijuana, all highly mutagenic (80). However, ESCC was virtually unknown until it emerged around the middle of the last century. The majority of young African patients, some aged 14-20 years, had never smoked or consumed alcohol. In Iran and China, a 
greater number of males smoke compared to females; however, the incidence in both sexes is similar in the highest risk regions. Historical reports concerning women at high risk in England, Wales, Scotland and Scandinavia repeatedly mention the abstinence of alcohol and tobacco (57). It therefore seems likely that the genesis of the majority of ESCC cases worldwide may be independent of tobacco and alcohol use.

Historically, exposure to a variety of chemicals, including heavy metals and various noxious agents, have been associated with an increased risk of ESCC (25). Currently, of greater consequence are the polycyclic aromatic hydrocarbons (PAHs) that are produced during the incomplete combustion of organic materials. Major sources are fried or flame-grilled food products, atmospheric air and occupational exposure. All high-risk rural populations are exposed to smoke from fires used for cooking and heating. PAHs and their metabolites can be detected in epithelial cells of the esophagus and in Iran, a strong dose-response association with risk of developing ESCC was demonstrated (81).

Numerous studies have incriminated the consumption of 'burning hot' food and beverages with an elevated risk of ESCC of approximately 2-fold $(82,83)$. Consumption of the herbal tea 'Mate' at very hot temperatures is strongly associated with the development of ESCC (1).

Poor oral health and tooth loss have also been associated with the risk of ESCC in several countries (5). A 30-year follow-up of the Linxian intervention trial revealed that those aged $<55$ years at baseline and who had had moderate tooth loss, had a 53\% higher risk of developing ESCC (84). A number of minerals do have profound effects on the formation and maintenance of teeth. Cariostatic elements thought to reduce loss when taken in beneficial amounts include F, P, Mo, vanadium (V), strontium (Sr), lithium (Li), Fe and B (85). When exposure is excessive, tooth loss is promoted by cadmium $(\mathrm{Cd})$, palladium ( $\mathrm{Pd}), \mathrm{Se}, \mathrm{Mn}$ and $\mathrm{Cu}$ in particular. The role of $\mathrm{Zn}$ is controversial; however, a deficiency is a known risk factor for oral and periodontal disease. Considering the above-mentioned effects of minerals, it is reasonable to conclude that all ESCC high-risk populations would be vulnerable to tooth loss.

Esophagitis is exceedingly frequent in all at-risk individuals. Commonly diagnosed in young children, it seems to progress with age as far as incidence and severity are concerned. It still manifests at the onset of malignancy. There is increasing interest and progress on the cancer-enhancing role of inflammation. It is not only involved in the early stages of tumorigenesis by inducing genetic instability, but also in late events since, for example, inflammatory mediators promote invasion and metastases (86). Evidence that anti-inflammatory drugs, such as aspirin and other non-steroidal drugs reduce the risk of ESCC, strongly supports this supposition (5). Numerous studies demonstrating the beneficial anti-inflammatory effects of aspirin and non-steroidal anti-inflammatory drugs (NSAIDs) on several types of cancer have been reviewed (87-89). In general, optimal suppression of carcinogenesis is observed with esophageal (both forms), gastric and colorectal cancers. Benefits are only evident after 3 years of therapy, and small doses are as effective as therapeutic dosages. Benefits exceeding a $40 \%$ reduction of risk were commonly reported; however, a large predominantly North American study only found a significant $25 \%$ reduction (90).
The main anticancer effect is attributed to the blockade of the cyclooxygenase 2 (COX2) pathway that involves cell proliferation, the inhibition of apoptosis and the induction of angiogenesis, although other actions are likely (91). Modern studies on inflammatory markers in ESCC vulnerable populations have not yet been reported, at least to the best of our knowledge. However, a study published in 1979 (31), found a significant elevation of antibodies to the $\mathrm{T}$ antigen, particularly in children, in the highest risk regions of the Eastern Cape (former Transkei), South Africa. This was ascribed to elevated levels of neuraminidase (produced by many bacteria) that was released into the circulation from septic lesions in diseased organs.

The role of oncogenic viruses, such as strains of HPV, has long been suspected to be involved in the etiology of ESCC. A recent review still did not provide any conclusive serological evidence of a definitive role for HPV (92). Unlike the high prevalence of HPV in cancer of the cervix, the detection rate in ESCC is highly variable even within high-risk areas, averaging $19.8 \%$ in Africa and $27.7 \%$ worldwide. The major oncogenic strain, HPV16, has only been detected in $11.4 \%$ of ESCC cases $(93,94)$. HPV viral genomes per cell are very low, if present at all, and the sequencing of viral-cellular DNA junctions has not been validated (93). Several other squamous cell cancers have a positive prognosis if found to be HPV-positive; however, this is not the case with ESCC $(94,95)$. It is currently accepted by the majority, that a role for HPV, if any, remains elusive.

HIV has assumed epidemic proportions, particularly in parts of Africa. Studies in Malawi and Zambia have noted concomitant increases in ESCC, and further South, it has been noted that ESCC patients that were HIV-positive presented with clinical carcinoma a decade younger than usual (96). Immunosuppression may play some role in recent times since the advent of HIV. Chronic gastric infection by H. pylori does reduce the acidity of gastric contents, and seemingly results in a reduction of Barrett's esophagus and adenocarcinomas. No beneficial effect on the incidence of ESCC has been reported to date, at least to the best of our knowledge.

Genetic studies are directed at identifying population subsets that could be vulnerable to ESCC. The findings await further assessment of the usefulness, but of value now are associations with alcohol metabolizing genes and even the identification of gene polymorphisms that may be useful in predicting the prognosis of patients (97).

Of great interest in ESCC is the important role that nutrition plays in epigenetic modifications related to DNA methylation, histone modifications and RNA interferences that contribute to the development of cancer and other diseases (98). Epigenetics implies heritable, but reversible changes in gene expression without modifications of the primary DNA sequence. Individual nutrients, but also plant compounds, can act as anti-carcinogenic agents by modulating properties that affect epigenetics. An emerging role for the effect of dietary intake on epigenetics has also been observed in inflammation and the modulation of cancer risk. Further nutri-epigenetic studies have revealed a strong association between nutrition, epigenetic mechanisms, inflammation and cancer risk $(98,99)$, implying that ESCC could be induced through the nutrition-inflammation-epigenetic pathway. 


\section{Discussion and conclusions}

The foregoing demonstrates that every known group or community worldwide which is at moderate or high risk of developing ESCC has experienced micronutrient malnutrition for prolonged periods of time. Even though the deficiencies are usually subclinical, attention is drawn to the exceedingly high esophageal epithelial cell replacement rate, requiring a good level of nutrition, to maintain the integrity of the epithelium. The consequences of protracted deficiencies are degenerative changes, particularly; atrophy, chronic esophagitis and irregular epithelial proliferations, all preceding malignant transformation. Such changes are often well-established during childhood in endemic regions.

The usual cause of deficiencies is the low micronutrient density of staple diets, such as those based on wheat and maize products (35). Such diets were common in isolated communities in Europe (7) and in indigent individuals and alcoholics throughout the Western world (15). In the epidemic regions of Asia and Africa maize, wheat and sometimes polished rice are also invariably used. Feeding these 'high risk' staples to animals markedly enhances induced carcinogenesis when compared to protective effects of 'low risk' staple diets used by equally indigent people (36). Dependence on 'soft' water derived from leached sedimentary strata also aggravates the risk.

The 'high risk' staples are deficient in vitamins $\mathrm{B}_{2}, \mathrm{~B}_{3}$ and the elements $\mathrm{Mg}$, Se, Mo and $\mathrm{Zn}$. These micronutrients are invariably deficient in all at-risk populations adequately studied. Each one individually has significant protective effects on induced esophageal carcinogenesis in animals (37). There is much molecular and biological evidence (not included in this review) that each of these nutrients play essential roles in not only maintaining the integrity of the epithelium, but also the ability to counteract carcinogenic progression. Undoubtedly, many other nutrients also participate, for example vitamin A and $\mathrm{Mn}$, the latter severely deficient in all epidemic regions. One of several Mn-based enzymes is the powerful antioxidant manganese superoxide dismutase. Mn deficiency is associated with susceptibility to human breast cancer (100), as well as buccal squamous cell cancer; its role in ESCC deserves more attention.

Significant carcinogenic exposures have not been identified in at-risk abstaining groups, such as isolated European woman, Plummer-Vinson patients, those with malabsorption syndromes, such as celiac disease, and nuns subsisting frugally. Malnutrition is however, common to all these patients and the carcinogenesis enhancing effects of chronic inflammation could be significant. Strong supportive evidence for this notion are the well-established benefits of consuming natural plant anti-inflammatory compounds, such as flavones in citrus, and the reduction of risk following aspirin and NSAID use that has been documented worldwide. Advances in nutri-epigenetics have done much to imply a primary role for nutrition and inflammation in ESCC causation.

While heavy smokers that are well nourished have a low risk, even light smokers following a poor diet or abusing alcohol have a markedly elevated risk (38). Individuals living in ESCC epidemic regions, such as Iranians, Chinese and Africans are all exposed to significant levels of carcinogenic mycotoxins.
This is due to the cultivation of wheat and maize on poor deficient soils that enhance the invasion of pathogenic fungi into the maturing grain. These carcinogens impacting on an esophageal epithelium chronically diseased due to nutritional deficiencies and esophagitis are likely the principle factors causing the highest cancer rates that are known worldwide for any cancer in both males and females. Naturally, a number of other factors, such as PAHs could contribute to a lesser extent.

The scenario mentioned above also clarified the sudden appearance of the disease in Africa. From being virtually unknown, it appeared within a few decades after high-yielding cultivars of maize became the main staple food, eventually attaining epidemic proportions within six decades. Such increases were documented in numerous centers wherever maize was cultivated and nowhere else. Odera et al (26) drew attention to how the adoption of some 'Western' customs of diets, food processing and cooking methods may be aggravating malnutrition.

Thus, the above-mentioned scenario can also explain all known unusual epidemiological features, such as the vastly variable effects of smoking and even the association between esophageal and gastric atrophy, as well as the occurrence of ESCC in chickens belonging to Chinese patients. Primary carcinomas usually arise at resistance sites or pathological strictures, possibly due to an impaired regenerative ability, as well as prolonged contact with ingesta.

Reducing the risk of ESCC will obviously include the minimization of deleterious lifestyle habits (5). Effective prevention will, however, depend on adequate micronutrient nutrition from a young age. We believe the inconclusive results of the very large nutrient supplementation study in Chinese subjects (43) was due to the fact that the elderly subjects studied already had transformed cells. Our pilot study (unpublished data) that examined the effects of supplements on patients with dysplasia was prematurely terminated due to the obvious aggravation of the dysplasia. Following this, human and experimental evidence indicating the potentiating effects, of in particular vitamin A, on transformed epithelial cells was reported (101). The vitamin is likely to be preventative in the preneoplastic period and should improve resistance to the esophagitis. However, while nutrients should be viewed as important in prevention, in general once established, cancers develop faster when well nourished.

An ideal prevention strategy would be to advocate a healthy diet to promote overall health (102). Fruits from deep rooted trees could be a good source of trace elements. However, a varied Western-type diet is not affordable to many low-income sectors, and the current production of such items has been estimated to be inadequate, supplying hardly half of the world's population. Yields of nutritious ancient staples are generally too low to cater for the needs of vastly increasing populations. Dependence on maize as a staple could be reduced by promoting nutrient-dense vegetables, such as sweet potatoes, which are even more nutritious than yams, a staple associated with an exceedingly low risk of the disease (35).

Nutrient supplementation in the Western world, particularly of maize meal and wheat flour, is currently extensive. Sweden commenced supplementation with $\mathrm{Fe}$ and $\mathrm{B}$ vitamins in the early 1950s with the subsequent reduction of upper alimentary tract cancers (57). Studies on the fortification of maize and 
wheat products in South Africa commenced in the 1980s; regulations now stipulate that the enrichment of these staples with 'vitamin A, thiamine, riboflavin, niacin, pyridoxine, folic acid, $\mathrm{Fe}, \mathrm{Zn}$ ' is now compulsory. Currently large decreases in the incidence of ESCC are being noted in all major medical facilities, but only in those low-income groups most dependent on fortified maize and wheat (103).

In this review, we have outlined the diversity of scenarios under which the occurrence of ESCC is evident. While multiple risk factors have been demonstrated for differentiated groups by extensive research, no universally applicable pathogenesis scenario has until now been elucidated. Noting the high mitotic index in the esophagus, the regenerative tempo required would likely need a high level of metabolic efficiency, dependent on good nutrition. In reviewing the range of studies and risk scenarios, and based on original research previously conducted, we propose that the primary determinant of ESCC susceptibility worldwide are changes induced in the epithelium by chronic multiple micronutrient deficiencies, including a number of the trace elements, and not just deficiencies of a few vitamins that commonly occur in several societies.

\section{Acknowledgements}

The authors appreciate the support received from the South African Medical Research Council and the Cancer Association of South Africa for some earlier relevant studies. The authors would also like to thank Delene van Rensburg for the competent preparation of the manuscript. Sincere appreciation is extended to Thelma van Rensburg for her encouragement and enduring countless hours alone while the author worked on this. The positive contributions of reviewers and scientific editors are much appreciated.

\section{Funding}

No funding was received.

\section{Availability of data and metadata}

Not applicable.

\section{Authors' contributions}

The review was conceived and initiated by ScJvR. SuJvR assisted with data accumulation, environmental issues, interpretation, comment and structure of the manuscript.

\section{Ethics approval and consent}

Not applicable.

\section{Patient consent for publication}

Not applicable.

\section{Competing interests}

The authors declare that they have no competing interests.

\section{References}

1. World Cancer Research Fund (WCRF) International: Diet, Nutrition, Physical Activity and Cancer: a Global Perspective. The Third Expert Report. WCRF International, London, 2018. https://www.wcrf.org/dietandcancer.

2. Liang H, Fan JH and Qiao YL: Epidemiology, etiology, and prevention of esophageal squamous cell carcinoma in China. Cancer Biol Med 14: 33-44, 2017.

3. Abnet CC, Arnold M and Wei WQ: Epidemiology of esophageal squamous cell carcinoma. Gastroenterology 154: 360-373, 2018.

4. North China TCG for research on the etiology esophageal cancer: The epidemiology and etiology of esophageal cancer in Northern China. Chin Med J 1: 167-183, 1975.

5. Kamangar F, Chow WH, Abnet CC and Dawsey SM: Environmental causes of esophageal cancer. Gastroenterol Clin North Am 38: 27-57.vii, 2009.

6. Cook P: Cancer of the oesophagus in Africa. Br J Cancer 25: 853-880, 1971

7. Craddock VM: Nutritional approach to oesophageal cancer in Scotland. Lancet 1: 217, 1987.

8. Schottenfeld D: Epidemiology of cancer of the esophagus. Semin Oncol 11: 92-100, 1984.

9. Wright JT and Richardson PC: Squamous carcinoma of the thoracic oesophagus in malabsorption syndrome. Br Med J 1: 540-542, 1967.

10. Warwick GP and Harington JS: Some aspects of the epidemiology and etiology of esophageal cancer with particular emphasis on the Transkei, South Africa. Adv Cancer Res 17: 81-229, 1973.

11. Jeurnink SM, Büchner FL, Bueno-de-Mesquita HB, Siersema PD, Boshuizen HC, Numans ME, Dahm CC, Overvad K, Tjønneland A, Roswall N, et al: Variety in vegetable and fruit consumption and the risk of gastric and esophageal cancer in the European prospective investigation into cancer and nutrition. Int J Cancer 131: E963-E973, 2012.

12. Steevens J, van den Brandt PA, Goldbohm RA and Schouten LJ: Selenium status and the risk of esophageal and gastric cancer subtypes: The Netherlands cohort study. Gastroenterology 138: 1704-1713, 2010.

13. Steevens J, Schouten LJ, Goldbohm RA and van den Brandt PA: Vegetables and fruits consumption and risk of esophageal and gastric cancer subtypes in the Netherlands Cohort Study. Int J Cancer 129: 2681-2693, 2011.

14. Tuyns AJ, Pequignot G and Jensen DM: Role of diet, alcohol and tobacco in oesophageal cancer, as illustrated by two contrasting high-incidence areas in the North of Iran and West of France. Front Gastrointest Res 4: 101-110, 1979.

15. Ziegler RG, Morris LE, Blot WJ, Pottern LM, Hoover R and Fraumeni JF Jr: Esophageal cancer among black men in Washington, DC II. Role of nutrition. J Natl Cancer Inst 67: 1199-1206, 1981.

16. Li JY: Epidemiology of esophageal cancer in China. Natl Cancer Inst Monogr 62: 113-120, 1982.

17. Yang CS: Research on esophageal cancer in China: A review. Cancer Res 40: 2633-2644, 1980.

18. Yang CS, Chen X and Tu S: Etiology and prevention of esophageal cancer. Gastrointest Tumors 3: 3-16, 2016.

19. Hormozdiari H, Day NE, Aramesh B and Mahboubi E: Dietary factors and esophageal cancer in the Caspian Littoral of Iran. Cancer Res 35: 3493-3498, 1975.

20. Kmet J and Mahboubi E: Esophageal cancer in the Caspian littoral of Iran: Initial studies. Science 175: 846-853, 1972.

21. Esophageal cancer studies in the Caspian littoral of Iran: Results of population studies-a prodrome. Joint Iran-International Agency for Research on Cancer Study Group. J Natl Cancer Inst 59: 1127-1138, 1977.

22. Burrell RJ, Roach WA and Shadwell A: Esophageal cancer in the Bantu of the Transkei associated with mineral deficiency in garden plants. J Natl Cancer Inst 36: 201-209, 1966.

23. Rose EF: Epidemiology of Oesophageal Cancer in Southern Africa. Adv Med Oncol Res Educ 9: 317-326, 1979.

24. Schaafsma T, Wakefield J, Hanisch R, Bray F, Schüz J, Joy EJ, Watts MJ and McCormack V: Correction: Africa's Oesophageal cancer Corridor: Geographic variations in incidence correlate with certain micronutrient deficiencies. PLoS One 10: e0142648, 2015.

25. Brown LM, Check DP and Devesa SS: Esophageal cancer. In The International Encyclopedia of Public Health. (eds) Quah S. R. WCC Elsevier, pp595-602, 2017.

26. Odera JO, Odera E, Githang'a J, Walong EO, Li F, Xiong Z and Chen XL: Esophageal cancer in Kenya. Am J Dig Dis (Madison) 4: 23-33, 2017. 
27. Burrell RJ: Esophageal cancer among Bantu in the Transkei. J Natl Cancer Inst 28: 495-514, 1962.

28. Marais J and Drewes E: The relationship between solid geology and oesophageal cancer distribution in the Transkei. Ann Geological Surv South Africa 1: 105-114, 1962.

29. Kibblewhite MG, Van Rensburg SJ, Laker MC and Rose EF Evidence for an intimate geochemical factor in the etiology of esophageal cancer. Environ Res 33: 370-378, 1984

30. Yang CY, Chiu HF, Tsai SS, Wu TN and Chang CC: Magnesium and calcium in drinking water and the risk of death from esophageal cancer. Magnes Res 15: 215-222, 2002.

31. Van Rensburg SJ, Laker MC, Nunn AJ, Nunn JR, Marasas WFO, Wehner FC and Vos GH: Environmental associations with oesophageal cancer in Transkei. Van Rensburg SJ. (ed.) South African National Cancer Association, 1979.

32. Stanwell Smith R: Naturally occurring Hazards. WHO/WSH/WWD/TA. 1. Geneva, 2001.

33. Yang CY, Chiu HF, Cheng MF, Tsai SS, Hung CF and Lin MC: Esophageal cancer mortality and total hardness levels in Taiwan's drinking water. Environ Res 81: 302-308, 1999.

34. Sengupta P: Potential health impacts of hard water. Int J Prev Med 4: 866-875, 2013.

35. Van Rensburg SJ: Epidemiologic and dietary evidence for a specific nutritional predisposition to esophageal cancer. J Natl Cancer Inst 67: 243-251, 1981.

36. Van Rensburg SJ, Hall JM and du Bruyn DB: Effects of various dietary staples on esophageal carcinogenesis induced in rats by subcutaneously administered N-nitrosomethylbenzylamine. J Natl Cancer Inst 75: 561-566, 1985.

37. Van Rensburg SJ, Hall JM and Gathercole PS: Inhibition of esophageal carcinogenesis in corn-fed rats by riboflavin, nicotinic acid, selenium, molybdenum, zinc, and magnesium. Nutr Cancer 8: 163-170, 1986.

38. Van Rensburg SJ, Bradshaw ES, Bradshaw D and Rose EF Oesophageal cancer in Zulu men, South Africa: A case-control study. Br J Cancer 51: 399-405, 1985.

39. Mobarhan S, Dowlatshahi K and Diba Y: Hair zinc levels from a normal population of northeast Iran with a high-incidence of esophageal-carcinoma (EC). Am J Clin Nutr 33: 940-940, 1980.

40. Siassi F, Pouransari Z and Ghadirian P: Nutrient intake and esophageal cancer in the Caspian littoral of Iran: A case-control study. Cancer Detect Prev 24: 295-303, 2000.

41. Yang CS, Miao J, Yang W, Huang M, Wang T, Xue H, You S, $\mathrm{Lu} \mathrm{J}$ and $\mathrm{Wu} \mathrm{J}$ : Diet and vitamin nutrition of the high esophageal cancer risk population in Linxian, China. Nutr Cancer 4 154-164, 1982

42. Mark SD, Qiao YL, Dawsey SM, Wu YP, Katki H, Gunter EW, Fraumeni JF Jr, Blot WJ, Dong ZW and Taylor PR: Prospective study of serum selenium levels and incident esophageal and gastric cancers. J Natl Cancer Inst 92: 1753-1763, 2000.

43. Taylor PR, Li B, Dawsey SM, Li JY, Yang CS, Guo W and Blot WJ Prevention of esophageal cancer: The nutrition intervention trials in Linxian, China. Linxian Nutrition Intervention Trials Study Group. Cancer Res 54 (7 Suppl): 2029S-2031S, 1994.

44. Lu H, Cai L, Mu LN, Lu QY, Zhao J, Cui Y, Sul JH, Zhou XF, Ding BG, Elashoff RM, et al: Dietary mineral and trace element intake and squamous cell carcinoma of the esophagus in a Chinese population. Nutr Cancer 55: 63-70, 2006.

45. Groenewald G, Langenhoven ML, Beyers MJ, du Plessis JP, Ferreira JJ and van Rensburg SJ: Nutrient intakes among rural Transkeians at risk for oesophageal cancer. S Afr Med J 60 964-967, 1981

46. Van Rensburg SJ, Benadé AS, Rose EF and du Plessis JP: Nutritional status of African populations predisposed to esophageal cancer. Nutr Cancer 4: 206-216, 1983.

47. Laker MC, Beyers CD, Van Rensburg SJ and Hensley M: Environmental associations with oesophageal cancer: An integrated model. In: Proceedings 10th National Congress of Soil Science Society of South Africa, Technical Communication, 1981

48. Norrish K: Geochemistry and mineralogy of trace elements In: Trace elements in soil-plant-animal systems. Nicolas D and Egan AR (eds). Academic Press, New York, NY, pp55-81, 1975.

49. Jaskiewicz K, Marasas WF, Rossouw JE, Van Niekerk FE and Heine Tech EW: Selenium and other mineral elements in populations at risk for esophageal cancer. Cancer 62: 2635-2639, 1988.

50. Wang A, Zhu C, Fu L, Wan X, Yang X, Zhang H, Miao R, He L, Sang $\mathrm{X}$ and Zhao $\mathrm{H}$ : Citrus fruit intake substantially reduces the risk of esophageal cancer: A meta-analysis of epidemiologic studies. Medicine (Baltimore) 94: e1390, 2015.
51. Zhao W, Liu L and Xu S: Intakes of citrus fruit and risk of esophageal cancer: A meta-analysis. Medicine (Baltimore) 97: e0018, 2018.

52. Coelho RC, Hermsdorff HH and Bressan J: Anti-inflammatory properties of orange juice: Possible favorable molecular and metabolic effects. Plant Food Hum Nutr 68: 1-10, 2013.

53. Asgary S, Keshvari M, Afshani MR, Amiri M, Laher I and Javanmard SH: Effect of fresh orange juice intake on physiological characteristics in healthy volunteers. ISRN Nutr 2014: 405867, 2014.

54. Van Rensburg SJ, Purchase IF, Rose EF and Roach WA: Structural alterations in the rat oesophagus epithelium after ingestion of the Transkei diet. S Afr Med J 47: 2361-2362, 1974.

55. Holmes GK, Stokes PL, Sorahan TM, Prior P, Waterhouse JA and Cooke WT: Coeliac disease, gluten-free diet, and malignancy. Gut 17: 612-619, 1976

56. Larsson LG, Sandströn A and Westling P: Relationship of Plummer-Vinson disease to cancer of the upper alimentary tract in Sweden. Cancer Res 35: 3308-3316, 1975.

57. Reddy BS, Cohen LA, McCoy GD, Hill P, Weisburger JH and Wynder EL: Nutrition and its relationship to cancer. Adv Cancer Res 32: 237-345, 1980.

58. Selby WS and Gallagher ND: Malignancy in a 19-year experience of adult celiac disease. Dig Dis Sci 24: 684-688, 1979.

59. Taufner G and Destefani AC: Prevalence of carcinoma in celiac patients. Canc Ther Oncol Int J 3: 555615, 2017.

60. Wynder EL and Fryer JH: Etiologic considerations of Plummer-Vinson (Paterson-Kelly) syndrome. Ann Intern Med 49: 1106-1128, 1958

61. Rose EF: A review of factors associated with cancer of the esophagus in Transkei. Prog Clin Biol Res 53: 67-75, 1981.

62. Dawsey SP, Tonui S, Parker RK, Fitzwater JW, Dawsey SM, White RE and Abnet CC: Esophageal cancer in young people: A case series of 109 cases and review of the literature. PLoS One 5: e14080, 2010

63. Hamilton D and Isaacson C: Oesophageal lesions at autopsy in black children. S Afr Med J 68: 407-408, 1985

64. Chang-Claude JC, Wahrendorf J, Liang QS, Rei YG, Muñoz N, Crespi M, Raedsch R, Thurnham DI and Correa P: An epidemiological study of precursor lesions of esophageal cancer among young persons in a high-risk population in Huixian, China. Cancer Res 50: 2268-2274, 1990.

65. Jaskiewicz K, Venter FS and Marasas WF: Cytopathology of the esophagus in Transkei. J Natl Cancer Inst 79: 961-967, 1987.

66. Sadeghi A, Behmard S, Shafiepoor H and Zeighmani E: Cancer of the esophagus in southern Iran. Cancer 40: 841-845, 1977.

67. Marasas W, Wehner F, Van Rensburg S and Van Schalkwyk D: Mycoflora of corn produced in human esophageal cancer areas in Transkei, southern Africa. Phytopathology 71: 792-796, 1981.

68. Sydenham EW, Thiel PG, Marasas WF, Shephard GS Van Schalkwyk DJ and Koch KR: Natural occurrence of some Fusarium mycotoxins in corn from low and high esophageal cancer prevalence areas of the Transkei, Southern Africa. J Agric Food Chem 38: 1900-1903, 1990.

69. Van Rensburg SJ, Marasas WFO, Gelderblom WCA, Thiel PG and Rabie CJ: Mycotoxins and oesophageal cancer. In: Proceedings of the 5th International Union of pure and applied chemistry symposium on mycotoxins and phycotoxins. Technical University, Vienna, 265-268, 1982.

70. Jaskiewicz K, van Rensburg SJ, Marasas WF and Gelderblom WC Carcinogenicity of Fusarium moniliforme culture material in rats. J Natl Cancer Inst 78: 321-325, 1987.

71. Marasas WF, Kriek NP, Fincham JE and Van Rensburg SJ: Primary liver cancer and oesophageal basal cell hyperplasia in rats caused by Fusarium moniliforme. Int J Cancer 34: 383-387, 1984.

72. Purchase I, Tustin R and Van Rensburg S: Biological testing of food grown in the Transkei. Food Cosmet Toxicol 13: 639-647, 1975.

73. Van Rensburg S, Cook-Mozaffari P, Van Schalkwyk D, Van der Watt JJ, Vincent TJ and Purchase IF: Hepatocellular carcinoma and dietary aflatoxin in Mozambique and Transkei. Br J Cancer 51: 713-726, 1985.

74. Jakszyn P and Gonzalez CA: Nitrosamine and related food intake and gastric and oesophageal cancer risk: A systematic review of the epidemiological evidence. World J Gastroenterol 12: 4296-4303, 2006.

75. Mhlongo SH, Mamba BB and Krause RW: Nitrosamines: A review on their prevalence as emerging pollutants and potential remediation options. Water SA 35: 735-740, 2009. 
76. Fan Y, Yuan JM, Wang R, Gao YT and Yu MC: Alcohol, tobacco, and diet in relation to esophageal cancer: The Shanghai Cohort Study. Nutr Cancer 60: 354-363, 2008.

77. Koh WP, Yuan JM, Sun CL, Lee HP and Yu MC: Middle-aged and older Chinese men and women in Singapore who smoke have less healthy diets and lifestyles than nonsmokers. J Nutr 135: 2473-2477, 2005.

78. Sakata K, Hoshiyama Y, Morioka S, Hashimoto T, Takeshita T and Tamakoshi A; JACC Study Group; Smoking, alcohol drinking and esophageal cancer: Findings from the JACC Study. J Epidemiol 15 (Suppl 2): S212-S219, 2005.

79. Sun Y, Zhang T, Wu W, Zhao D, Zhang N, Cui Y, Liu Y, Gu J, Lu P, Xue F, et al: Risk factors associated with precancerous lesions of esophageal squamous cell carcinoma: A screening study in a high risk Chinese population. J Cancer 10: 3284-3290, 2019.

80. Wehner FC, Van Rensburg SJ and Thiel PG: Mutagenicity of marijuana and Transkei tobacco smoke condensates in the Salmonella/microsome assay. Mutat Res 77: 135-142, 1980.

81. Abedi-Ardekani B, Kamangar F, Hewitt SM, Hainaut P Sotoudeh M, Abnet CC, Taylor PR, Boffetta P, Malekzadeh R and Dawsey SM: Polycyclic aromatic hydrocarbon exposure in oesophageal tissue and risk of oesophageal squamous cell carcinoma in north-eastern Iran. Gut 59: 1178-1183, 2010.

82. Andrici J and Eslick GD: Hot food and beverage consumption and the risk of esophageal cancer: A meta-analysis. Am J Prey Med 49: 952-960, 2015.

83. Tai WP, Nie GJ, Chen MJ, Yaz TY, Guli A, Wuxur A, Huang QQ, Lin ZG and $\mathrm{Wu}$ J: Hot food and beverage consumption and the risk of esophageal squamous cell carcinoma: A case-control study in a northwest area in China. Medicine (Baltimore) 96: e9325, 2017.

84. Zhang S, Yu P, Wang JB, Fan JH, Qiao YL and Taylor PR: Association between tooth loss and upper gastrointestinal cancer: A 30-year follow-up of the Linxian Dysplasia Nutrition Intervention Trial Cohort. Thorac Cancer 10: 966-974, 2019.

85. Dogan MS: Relation of trace elements on dental health.SalehHE-DM and El-Adham E (eds). BoD-Books on Demand, 2018. https://www. intechopen.com/books/trace-elements-human-health-and-environment/relation-of-trace-elements-on-dental-health. IntechOpen, 2018. Accessed September 5, 2018

86. Castiglioni S and Maier JA: Magnesium and cancer: A dangerous liaison. Magnes Res 24 (Suppl): S92-S100, 2011

87. Bosetti C, Rosato V, Gallus S, Cuzick J and La Vecchia C: Aspirin and cancer risk: A quantitative review to 2011. Ann Oncol 23: 1403-1415, 2012.

88. Cuzick J, Thorat MA, Bosetti C, Brown PH, Burn J, Cook NR, Ford LG, Jacobs EJ, Jankowski JA, La Vecchia C, et al: Estimates of benefits and harms of prophylactic use of aspirin in the general population. Ann Oncol 26: 47-57, 2014.

89. Sun L and Yu S: Meta-analysis: Non-steroidal anti-inflammatory drug use and the risk of esophageal squamous cell carcinoma. Dis Esophagus 24: 544-549, 2011.

90. Qiao Y, Yang T, Gan Y, Li W, Wang C, Gong Y and Lu Z: Associations between aspirin use and the risk of cancers: A meta-analysis of observational studies. BMC Cancer 18: 288, 2018.
91. Dachineni R, Kumar DR, Callegari E, Kesharwani SS, Sankaranarayanan R, Seefeldt T, Tummala $H$ and Bhat GJ: Salicylic acid metabolites and derivatives inhibit CDK activity: Novel insights into aspirin's chemopreventive effects against colorectal cancer. Int J Oncol 51: 1661-1673, 2017.

92.Bucchi D, Stracci F, Buonora N and Masanotti G: Human papillomavirus and gastrointestinal cancer: A review. World J Gastroenterol 22: 7415-7430, 2016

93. Geßner A, Borkowetz A, Baier M, Göhlert A, Wilhelm TJ, Thumbs A, Borgstein E, Jansen L, Beer K, Mothes H and Dürst M: Detection of HPV16 in esophageal cancer in a high-incidence region of Malawi. Int J Mol Sci 19: pii: E557, 2018.

94. Guo L, Liu S, Zhang S, Chen Q, Zhang M, Quan P and Sun XB: Human papillomavirus-related esophageal cancer survival: A systematic review and meta-analysis. Medicine (Baltimore) 95: e5318, 2016

95. da Costa AM, Fregnani JHTG, Pastrez PRA, Mariano VS, Silva EM, Neto CS, Guimarães DP, Villa LL, Sichero L, Syrjanen KJ and Longatto-Filho A: HPV infection and p53 and p16 expression in esophageal cancer: Are they prognostic factors? Infect Agent Cancer 12: 54, 2017.

96. Loots E, Sartorius B, Madiba TE, Mulder C and Clarke DL: Oesophageal squamous cell cancer in a South African tertiary hospital: A risk factor and presentation analysis. S Afr J Surg 55 42-46, 2017.

97. Sun L, Wei L, Wei L and Li D: Correlation between Bax gene polymorphisms and esophagus cancer. Oncol Lett 16: 7097-7101, 2018.

98.Lundstrom K: Nutrition and epigenetics. EC Nutrition 8: 109-115, 2017.

99. Joseph PV, Abey SK and Henderson WA: Emerging role of Nutri-Epigenetics in inflammation and cancer. Oncol Nurs Forum 43: 784-788, 2016.

100. Shen F, Cai WS, Li JL, Feng Z, Cao J and Xu B: The association between deficient manganese levels and breast cancer: A meta-analysis. Int J Clin Exp Med 8: 3671-3680, 2015.

101. Van Rensburg SJ, Kruger EF, Louw MEJ and Du Plessis JP: Vitamin A status and esophageal cancer risk: Epidemiologic and experimental evidence for a positive association. Nutr Rep Internat 24: 1123-1131, 1981.

102. Abnet CC, Corley DA, Freedman ND and Kamangar F: Diet and upper gastrointestinal malignancies. Gastroenterology 148 1234-1243.e4, 2015

103. Bizos D, Morgan H, Motha N, Makda M, Domingo A, Tiedt S, Wing J, Munanga M, Tembo J, Hale M and Bizos D: Comparison of the incidence of oesophageal cancer in two 6-year periods from selected hospitals in and around Gauteng Province, South Africa. S Afr J Surg 53: 55-58, 2015.

This work is licensed under a Creative Commons Attribution-NonCommercial-NoDerivatives 4.0 International (CC BY-NC-ND 4.0) License. 